\title{
Child Trafficking: Psychological Effect and the Need for Counselling
}

\author{
B. Vijayasree ${ }^{1}$, Sivvala Radhika ${ }^{2}$ \\ ${ }^{1}$ CEO, SERVICE Organization, NGO, Guntur, AP, India \\ ${ }^{2}$ Ph.D, Non UGC Research Fellow, Dept of Psychology, Osmania University, Hyderabad, India
}

\begin{abstract}
This paper discusses the child trafficking which is one of the major problems in India and the need for counseling. Trafficking is violation of human right and most of the children trafficked are forced into cheap, controllable labor, work in home, farms and many of them forced into sex and drug trade. The child's experiences with trafficking can lead to lasting effect on the emotional and mental health of the child. Protective environment should be built to restore child back into normalcy. This calls for need of counseling with focus on availability of social supports, parental emotional functioning, and the child's resilience and coping skills.
\end{abstract}

Keywords: child trafficking, psychological effect, need for counseling

\section{Introduction}

Human trafficking is one of the major problems in India over the last decade and the volume of trafficking has increased. After arms and drug smuggling it has become lucrative criminal trade undertaken by highly organized criminals. India is a source, transit and destination country for women and children trafficked for the purpose of sexual exploitation. Trafficking is quite often equated with sexual exploitation, but it is important to acknowledge that not all trafficking results in sexual exploitation of women and children. Trafficking takes place for a range of exploitative purposes, including labour or fraudulent adoption. In India a large number of children are trafficked not only for the purpose of sexual exploitation but also for other forms of exploitation that includes servitude of various kinds, such as, domestic labour, industrial labour, agricultural labour, begging, organ trade and false marriage.

Human trafficking and commercial sexual exploitation (CSE) are major social problems. Children are routinely sold like commodities in a multibillion dollar industry that operates with near impunity (International Labour Organization-International Programme on the Elimination of Child Labour [ILO-IPEC], 2001; United Nations Office of Drugs and Crime [UNODC], 2006). CSE is the most widely recognized form of child trafficking, and because heterosexual prostitution remains the largest and most profitable form of CSE, girls are primarily affected (International Organization for Migration [IOM], 2007). Children trafficked into one form of labor are often subsequently sold into another, as with girls who are recruited to work in factories or domestic work but who are subsequently sold into brothels.

\section{Objective of the Study}

To understand the psychological impact of trafficking on children and analyze the importance of counseling for good mental health of the victims

\section{Psychological Impact of Trafficking}

The psychological effects can be devastating because of the trauma associated with trafficking and, if left unaddressed, can undermine victims' recovery and potentially contribute to vulnerability to re-victimization. Traffickers use psychological manipulations and coercive methods to maintain control over their victims and to make their escape virtually impossible by destroying their physical and psychological defenses. Reported methods include physical, sexual, and psychological violence; isolation; deployment in areas unknown to them; dependence on alcohol or drugs; controlled access to food and water; and monitoring through the use of weapons, cameras, and dogs (IOM, 2007; Zimmerman et al., 2003). Although empirical research (i.e., rigorous academic research) on the impact of trafficking on children is lacking, numerous accounts suggest that the emotional and physical trauma and unrelenting abuse and fear present a grave risk to physical, psychological, spiritual, and social-emotional development (Bertone, 2000; End Child Prostitution and Trafficking International [ECPAT], 2005, 2006a; ILO-IPEC, 2001; Scarpa, 2005). Case studies of victims suggest that CSE is _the most physically and emotionally damaging for the victim because of the persistent physical, sexual and psychological abuse that accompanies it on a daily basis“" (IOM, 2007, p. 25). Some children die as a result of abuse and exploitation; others disappear (Mitchels, 2004; UNODC, 2006). In addition to these case studies and reports, research on child maltreatment can shed light on the plight of children who are trafficked. These studiessuggest a strong link between child maltreatment and maladaptive physical and psychological outcomes(Bottoms \&Quas, 2006). Children who have been exposed to complex trauma, such as prolonged physical abuse, sexual abuse, emotional abuse and neglect, violence, and torture, are at increased risk for a number of symptoms and behavioral characteristics, including attachment, biological integrity, emotional regulation, dissociative adaptations, behavior, cognitive functioning, and selfconcept.

Living consistently in fear, being captive in a country without language skills, consistent threats to oneself and 


\section{International Journal of Science and Research (IJSR) \\ ISSN (Online): 2319-7064 \\ Index Copernicus Value (2013): 6.14 | Impact Factor (2014): 5.611}

one's family should one escape, etc., creates feelings of isolation, a lack of control over one's life, a sense of helplessness and hopelessness, low self-esteem, self-worth and self-respect, self-blame, depression, anxiety, guilt, anger, rage, difficulty sleeping or insomnia, fear or hatred of men, paranoia, loss of appetite, lack of energy, dreams or nightmares about being abused, attacked or resold, lack of trust in and suspicion of people, suicidal thoughts, the desire to punish the traffickers, feelings of being trapped, easily startled, and always being on guard. There are also feelings of disgust and shame, worthlessness and numbness, attempts at self-injury by cutting, drug overdoses

\section{Psychological Rehabilitation}

Psychology can also play an important role in the recovery, rehabilitation, and reintegration of children who have been trafficked. First and foremost is the need to establish data collection and reporting procedures to rapidly identify victims. We must also develop cooperative efforts to facilitate the timely return of children to their communities. Young victims should be immediately reunited with their families, unless consultation with the child and an assessment of risk suggests this in not in the child's best interest. If children cannot be safely reunited, appropriate arrangement for their care should be made. Specialized interventions programs must be developed, implemented, and evaluated to effectively address the physical, psychological, social, and educational needs of children who have been trafficked and facilitate their reintegration into their families, schools, and communities (IPU \& UNICEF, 2005; United Nations Division for the Advancement of Women, 2002; UNICEF, 2005).

Counseling should focus on availability of social supports, parental emotional functioning, and the child's resilience and coping skills. Counseling would allow victims to share their experiences so that we might learn about the types of support and protection services that children need. Psychological research could also address effective techniques for interviewing victims of trafficking.

Psychologists with expertise in child development can also contribute to research, social policy, and practice by exploring the range of assistance needed by victims of child trafficking. These include proper identification and protection from further physical and psychological harm, referral and reintegration assistance, cooperation with law enforcement authorities, and the essential components of successful reintegration programs (e.g., safety measures, effective communication strategies, education, specialized health services, psychological counseling, information on human rights, and legal support; Bjerkan, Dyrlid, NikolicRistanovic, \&Simeunovic-Patic, 2005; ECPAT, 2006a

Finally, given the multidimensional effects of trafficking on an individual's health, psychologists could be involved with other interventions that are part of the reintegration process. A multidisciplinary service approach to recovery would recognize that the emotional well-being of an individual or group can be affected by acting on the social factors that surround them (IOM, 2007). A psychosocial approach could focus on the link between social-community and cultural factors and individual emotional well-being and include interventions that target the child's family situation and home environment, the child's educational and vocational needs, health problems, communities, and the broader culture and society (ECPAT, 2006a, 2007; Elliot \&Urquiza, 2006; Zimmerman et al., 2003). For example, children with health problems, including those with HIV and AIDS, need specialized treatments that are culturally appropriate and their caregivers need the necessary resources to ensure their proper care (e.g., financial, educational, health, and psychosocial support).

Counselling should focus on counselling for child maltreatment, impact of trafficking and CSE on children (Toth\&Cicchetti, 2006). It also should provide guidance for a number of practice areas (e.g., child interviewing, treatment for childhood PTSD, and treatment of sexually reactive behavior; Bottoms \&Quas, 2006).

\section{Conclusion}

From this study it can be concluded that immediate assistance and psychological intervention in form of counseling is important and necessary. Psychological distress (depression, in particular) may decrease from initial levels, but, for many they remain life-altering remnants of a traumatic period. This aftermath often has the power to affect sense of control over themselves, their future and their ability to engage in social settings. Hence it can be concluded that counseling is the need of the hour to help the child trafficking victim to become more resilient and restore their self efficacy.

\section{References}

[1] Chase, E., \& Statham, J. (2005).Commercial and sexual exploitation of children and young people in the UK-A review. Child Abuse Review, 14, 4-25

[2] Farr, K. (2005). Sex trafficking: The global market in women and children. New York: Worth

[3] Getu, M. 2006. Human Trafficking and Development: The Role of Microfinance." 144

[4] Haspels, N., \&Suriyasarn, B. (2003). Promotion of gender equality in action against child labour and trafficking: A practical guide for organizations. Bangkok, Thailand: International Labour Organization

[5] Lalor, K. (2004). Child sexual abuse in Tanzania and Kenya. Child Abuse and Neglect, 28, 833-844

[6] Miko, FT. 2003. Trafficking In Women And Children: The US And International Response." 2

[7] Rafferty, Y. (2007). Children for sale: Child trafficking in Southeast Asia. Child Abuse Review, 16, 401-422

[8] Scarpa, S. (2005). Child trafficking: The worse face of the world. Global Migration Perspectives, No. 40.Global Commission on International Migration (GCIM). Retrieved December 8, 2006 